\title{
Testing the regulatory framework in South Africa - a single-blind randomized pilot trial of commercial probiotic supplementation to standard therapy in women with bacterial vaginosis
}

\author{
Anna-Ursula Happel ${ }^{1,2^{*}}$ (D), Ravesh Singh ${ }^{3,4}$, Nireshni Mitchev ${ }^{3}$, Koleka Mlisana ${ }^{3,4}$, Heather B. Jaspan ${ }^{1,5}$, \\ Shaun L. Barnabas ${ }^{1,6+}$ and Jo-Ann S. Passmore 1,2,4† $^{1,4}$
}

\begin{abstract}
Background: Bacterial vaginosis (BV) increases HIV risk and adverse reproductive outcomes. Standard-of-care (SOC) for BV are antibiotics; however, cure rates are low. Probiotics for vaginal health may be useful in improving cure and recurrence although the regulatory framework governing probiotics and the conduct of randomized clinical trials to evaluate these has not been established in South Africa. We performed an exploratory single-blind trial evaluating a commercial oral-vaginal-combination probiotic as adjunct to SOC for BV treatment.

Methods: Women with symptomatic vaginal discharge were screened for BV and common sexually transmitted infections (STIS). BV+ (Nugent 7-10) but STI- women were randomized to vaginal metronidazole alone $(n=12)$ or to metronidazole followed by a commercial oral/vaginal probiotic $(n=18)$. The primary qualitative outcome was to test the regulatory landscape for conducting randomized probiotic trials in South Africa; and acceptability of vaginal application by women. BV cure at 1 month (Nugent $\leq 3$ ) was the primary quantitative endpoint. Secondary quantitative endpoints were BV recurrence, symptoms, vaginal microbiota and genital cytokine changes over 5 months post-treatment.

\footnotetext{
*Correspondence: anna.happel@uct.ac.za

'Shaun Barnabas and Jo-Ann Passmore are co-last authors and contributed equally to the study

'Division of Medical Virology, Faculty of Health Sciences, Institute of

Infectious Disease and Molecular Medicine, University of Cape Town, Anzio Road, Observatory, Cape Town 7925, South Africa

${ }^{2}$ NRF-DST CAPRISA Centre of Excellence in HIV Prevention, Cape Town, South Africa

Full list of author information is available at the end of the article
}

(c) The Author(s). 2020 Open Access This article is licensed under a Creative Commons Attribution 4.0 International License, which permits use, sharing, adaptation, distribution and reproduction in any medium or format, as long as you give appropriate credit to the original author(s) and the source, provide a link to the Creative Commons licence, and indicate if changes were made. The images or other third party material in this article are included in the article's Creative Commons licence, unless indicated otherwise in a credit line to the material. If material is not included in the article's Creative Commons licence and your intended use is not permitted by statutory regulation or exceeds the permitted use, you will need to obtain permission directly from the copyright holder. To view a copy of this licence, visit http://creativecommons.org/licenses/by/4.0/ The Creative Commons Public Domain Dedication waiver (http://creativecommons.org/publicdomain/zero/1.0/) applies to the data made available in this article, unless otherwise stated in a credit line to the data. 


\begin{abstract}
(Continued from previous page)
Results: The South African Health Products Regulatory Authority (SAHPRA) reviewed and approved this trial. As probiotics continue to be regulated as health supplements in South Africa, SAHPRA required a notification application for this trial. Acceptability and adherence to the oral and vaginal application of the probiotic were high, although women reported a preference for oral capsules. 44.8\% of women cleared BV one-month post-treatment, and no significant differences in $\mathrm{BV}$ cure $(\mathrm{RR}=0.52,95 \% \mathrm{Cl}=0.24-1.16)$, recurrence, vaginal $\mathrm{pH}$, symptoms, microbiota or vaginal IL-1 a concentrations were found between SOC and intervention groups in this pilot study with an over-the-counter product.
\end{abstract}

Conclusion: Navigation of the SAHPRA registration process for evaluating a commercial probiotic in a randomised trial laid the foundation for planned larger trials of improved probiotic products for vaginal health in South Africa. Although adherence to the vaginally delivered probiotic was high, women preferred oral application and we recommend that improvements in the content and method of application for future probiotics for vaginal health should be considered.

Trial registration: This trial was registered on 17 October 2017 with the South African National Clinical Trial Register (http://www.sanctr.gov.za/; BV-trial1; DOH-27-1117-5579).

Keywords: BV, Probiotics, Regulation, South Africa, SAHPRA, Vaginal health, Randomized trial

\section{Background}

Bacterial vaginosis (BV) is the most common genital condition of women of reproductive age [1], defined by a rapid shift in the composition of vaginal bacterial communities from a Lactobacillus-dominated to a polymicrobial microbiota, compromising a mixture of diverse anaerobes, such as Prevotella, Gardnerella, BVAB1, Sneathia, and Megasphera spp. [2-4]. It increases risk of adverse pregnancy outcomes $[5,6]$ and acquisition and transmission of sexually transmitted infections (STIs), including HIV $[7,8]$, possibly due to the associated genital inflammation [9]. Antibiotics remain the standard-ofcare (SOC) for treating BV although more than $50 \%$ of women experience recurrent episodes within 6-12 months $[10,11]$. While most countries treat BV as part of syndromic management [12], more than $85 \%$ of BV cases are asymptomatic but nonetheless associated with significantly elevated genital inflammation [13]. In Africa, where epidemics of BV, STIs and HIV converge [14] and genital inflammation associated with even asymptomatic BV may increase HIV risk $[8,15]$, an urgent need to rethink and improve the SOC for treating BV exists.

Several clinical studies have evaluated Lactobacilluscontaining probiotics as an adjunct to antibiotics in treating BV $[16,17]$. However, there is clinical equipoise as to whether adjunctive probiotics improve BV cure and/or recurrence rates [18]. As the microbial composition of the lower female genital tract (FGT) in health and dysbiosis may be geo-adapted, with regional differences in diet, vaginal insertion, hygiene practices and host genetics possibly shaping these [19-21], it is critical to conduct trials in South Africa to test the effectiveness of probiotics for vaginal health in a local context. While randomized controlled trials (RCTs) assessing the effects of probiotics on BV management have been performed in several other African countries [22, 23], only one exploratory pilot study has recently been performed in South Africa, although with a European product that is not locally available [24].

In South Africa, the registration of medicines, probiotics and health supplements along with their use in clinical trials is regulated by the South African Health Products Regulatory Authority (SAHPRA), but none of the $>100$ currently available over-the-counter (OTC) probiotics [25] has previously been formally reviewed by SAHPRA and no trial evaluating the impact of probiotics on health outcomes has been SAHPRAapproved or acknowledged. Gaining understanding of the regulatory framework for testing and introducing new vaginal geo-adapted probiotics intended for vaginal application is critical. Here, we describe the process and acceptability of conducting an exploratory single-blind trial in South African women diagnosed with BV. The main qualitative outcome was to test the South African regulatory framework and local acceptability of conducting probiotic trials for $\mathrm{BV}$ with vaginal application. BV cure in women receiving probiotic in adjunct to SOC compared to SOC only was an exploratory quantitative outcome, together with understanding of adherence, changes in vaginal $\mathrm{pH}$, clinical symptoms, vaginal cytokine concentrations and bacterial microbiota in both groups.

\section{Methods}

\section{Regulatory approval}

This trial was submitted and approved by SAHPRA (SAHRPA Ref 20,161,201; PI: S. Barnabas), the University of Cape Town's (UCT) Human Research Ethics Committee (HREC Ref 706/2016) and the South African 
National Health Research Ethics Council (NHREC Ref 4579) and registered with the South African National Clinical Trials Register of the Department of Health (DOH-27-1117-5579).

\section{Eligibility criteria}

Women were recruited from a South African public sector STI clinic (Spencer Road Clinic) and from the UCT Student Wellness Centre in Cape Town, South Africa. Eligible women were $18-45$ years old and seeking care for vaginal discharge. All eligible women were tested for BV (by Nugent scoring) and STIs, including C. trachomatis, $N$. gonorrhoea, T. vaginalis, and M. genitalium by TaqMan ${ }^{\circ}$ Assays (Fast Track Diagnostics). Inclusion criteria were being BV positive (Nugent 7-10) but negative for any STI. Exclusion criteria included being pregnant, breastfeeding, pelvic inflammatory disease, living with HIV, having a known allergy to metronidazole, and/or currently using any other antibiotics or natural remedies in the urogenital area. Women who acquired an STI or had recurrent BV over the course of the trial were referred for treatment but not excluded, and any concomitant medication (including antibiotics) taken over the course of the study was recorded. Study visits were planned such that women were not menstruating nor reported having unprotected sex or douching in the $48 \mathrm{~h}$ prior to sampling. All women were tested for HIV (Rapid Anti-HIV (1\&2) test; InTec products, Inc., China) and pregnancy (hCG Pregnancy test; Homemed ${ }^{\mathrm{pw}}$, South Africa) at screening.

\section{Sample size calculations}

This was an exploratory study designed to establish the regulatory landscape to conduct probiotic trials in South Africa, with additional exploratory quantitative analyses. We based our sample size calculation of 30 women on cure rates from previous studies [22, 26]. Petricevic et al. (2008) reported a decline in BV in $83 \%$ of intervention compared to $35 \%$ in control arm participants after oral application of $300 \mathrm{mg}$ clindamycin for 7 days followed by vaginal capsules containing $10^{9} \mathrm{CFU}$ of L.casei rhamnosus for 7 days and Anukam et al. (2006) reported cure rates of $88 \%$ in the treatment group and $40 \%$ in the control group after administering $500 \mathrm{mg}$ metronidazole orally for 7 days followed by oral administration of L.rhamnosus and L.reuteri (each $10^{9} \mathrm{CFU}$ ) for 30 days. In both studies, cure rates were assessed 30 days after the last administration of the probiotics. Since we applied probiotics both orally and vaginally and for 15 days, we expected the cure rates to be similar. Thus, we anticipated a sample size of 30 women (enrolled in a 2:3 ratio in SOC: intervention arms) would detect the above difference in proportions ( 0.83 vs. 0.35$)$ with $75 \%$ power at $\alpha=0.05$, which we considered sufficient for this pilot trial.

\section{Randomisation and blinding}

Randomisation was performed using the pseudorandom number generator in Microsoft Excel 2016 (MT19937) by research pharmacists at the UCT CRC who were not involved with clinical procedures and/or screening processes and only dispensed the investigational product. Researchers and laboratory staff involved in sample and data analysis were blinded to the randomisation process. The research nurse who conducted the clinic visits was not blinded as she interacted directly with participants. After the database lock and a primary blinded analysis, the unblinded treatment allocations were released.

\section{Dosing regimens}

Eligible women either received topical metronidazole only $(0.75 \%$ gel, $5 \mathrm{~g}$ vaginally, once a day for 5 days) or topical metronidazole followed by a 15-day treatment course of a probiotic marketed in South Africa to improve vaginal health (intervention group), which included 5 days of oral probiotic capsules followed by 10 days of oral capsules together with twice daily vaginal spray. The oral capsules and each metered dose of the vaginal spray contained lyophilized $L$. acidophilus, $L$. rhamnosus GG, B. bifidum and B. longum at $\geq 2 \times 10^{9}$ colony-forming units (CFU).

\section{Laboratory quality control of the probiotic lot used in the study}

The contents and concentrations of each microbial species of the probiotic lot were confirmed prior to initiation of the trial (Additional Figure 1). Briefly, one full oral or vaginal dose was dissolved in Brain Heart Infusion broth (supplemented with $0.1 \%$ starch and $1 \%$ yeast, $\mathrm{sBHI}$ ), serially diluted and plated in triplicates onto sBHI agar plates. Plates were incubated at $37^{\circ} \mathrm{C}$ for $48 \mathrm{~h}$ under anaerobic conditions (using Oxoid ${ }^{\text {Tw }}$ AnaeroGen $^{\text {tw }} 2.5 \mathrm{~L}$ Sachets, Thermo Fisher Scientific Inc., USA). The CFU per well were counted and the average concentration per dose was calculated. Contents were confirmed by MALDI-TOF (MALDI Biotyper, Bruker Daltonik, USA).

\section{Clinical procedures and sample collection}

At screening, a vulvo-vaginal swab for STI testing and a posterior fornix and lateral wall swab to screen for BV by Nugent Scoring were collected. At enrolment (pretreatment), and 1, 3 and 5 months post-treatment, genital samples were collected in the following order under speculum examination: (1) a vulvo-vaginal swab for STI testing; (2) a posterior fornix and lateral wall swab to screen for BV (by Nugent Scoring) and to measure vaginal $\mathrm{pH}$ (using a colour-fixed indictor $\mathrm{pH}$ strip; Macherey 
Nagel); and $(3,4)$ two lateral wall swabs to measure genital IL- $1 \alpha$ (as marker of genital inflammation, by ELISA) and vaginal microbiota (by qPCR). In addition, women completed a questionnaire on demographics, reproductive health and sexual behaviour at enrolment, and a questionnaire assessing feasibility, acceptability and adherence to the administered products, vaginal symptoms and adverse events at follow up visits. Product preference was assessed at the final visit by questionnaire (Additional File 1). Adherence was measured by self-report in medication diaries and questionnaires, as well as return of empty packages at the one-month follow-up visit.

\section{Testing for STIs and BV}

The commercial TaqMan ${ }^{\bullet}$ FTD STD9 (Fast Track Diagnostics, Luxembourg) kit, performed as per manufacturer's instructions, was used to test for $N$. gonorrhoeae, C. trachomatis, T. vaginalis and M. genitalium. As positive controls, genomic DNA extracts from the following ATCC $^{\circ}$ strains were included: $N$. gonorrhoeae (ATCC ${ }^{\circ}$ 700825), C. trachomatis (ATCC ${ }^{\circ}$ VR-885), T. vaginalis (ATCC 30001) and M. genitalium (ATCC 33530). BV was diagnosed by Gram staining of vaginal smears and Nugent Scoring. Slides were assessed microscopically and assigned a score between 0 and 10, with a score of 0-3 considered BV negative, 4-6 intermediate microbiota, and 7-10 BV positive.

\section{Clinical outcomes}

While this study was intended to test the regulatory landscape to conduct probiotic trials in South Africa and acceptability/preference of the probiotic administration for vaginal health, BV cure rates were considered (defined as having Nugent $\leq 3$ one-month post-treatment) as primary quantitative endpoint. In addition, other secondary endpoints included adherence, recurrence, changes in vaginal $\mathrm{pH}$, concentrations of bacterial species contained in the administered probiotic (L. acidophilus, L. rhamnosus, B. bifidum and $B$. longum) and bacterial species associated with vaginal health (L. crispatus, L. jensenii, L. iners, L. gasseri, L. vaginalis, L. mucosae) or BV (G. vaginalis, P. bivia, BVAB2, Megasphaera 1 and A. vaginae), and IL-1 $\alpha$ concentrations (as a bio-marker of genital inflammation) over 5 months post-treatment.

\section{Measuring vaginal bacterial concentrations}

Concentrations of vaginal Lactobacillus spp. (including $L$. crispatus, $L$. jensenii, $L$. iners, $L$. gasseri, $L$. vaginalis, $L$. mucosae), BV-associated organisms (including G. vaginalis, P. bivia, BVAB2, Megasphaera 1 and A. vaginae), and bacterial species contained in the administered probiotic product (including $L$. acidophilus, L. rhamnosus, B. bifidum and B. longum) were assessed using commercially available Applied Biosystems ${ }^{\text {Ta }}$ TaqMan $^{\circ}$ Assays (Thermo Fisher Scientific Inc., USA; Assay IDs Ba04646245_s1, Ba04646258_s1, Ba04646257_s1, Ba04646234_s1 for Lactobacillus spp. and Ba04646236_s1, Ba04646278_s1, Ba04646229_s1, Ba04646230_s1, Ba04646222_s1 for BVassociated species). For $L$. vaginalis (KF875988.1) and $L$. mucoasae (NR_024994.1) Thermo Fisher Scientific designed custom probes based on the referenced nucleotide sequence. The TaqMan probe sequences for $L$. acidophilus and L. rhamnosus (Haarman and Knol [27]), as well as B. bifidum and B. longum (Haarman and Knol [28]) were previously published. Using an ABI 7500 Real-Time PCR Detection System (Thermo Fisher Scientific Inc., USA), we quantified each of the targets. The quantification was performed using amplicons generated from plasmids for each of the targets TaqMan $^{\text {Th }}$ Vaginal Microbiota Extraction Control). Serial dilutions, ranging from $10^{0}$ to $10^{9}$ molecules per $\mu \mathrm{l}$ of sample were used to generate standard curves. Bacterial concentrations were normalized to $16 \mathrm{~S}$ rRNA gene concentrations, as recommended by the manufacturer.

\section{Measuring cervicovaginal IL-1a concentrations}

Samples were thawed on ice and filtered by centrifuging at $1950 \mathrm{~g}$ for $10 \mathrm{~min}$ at $4{ }^{\circ} \mathrm{C}$ in SPIN-X $0.2 \mu \mathrm{M}$ cellulose acetate filters to exclude mucus and debris prior to performing the ELISA. Human IL- $1 \alpha$ concentrations were measured using a commercial ELISA (E-EL-H008, Elabscience ${ }^{\bullet}$, USA), according to the manufacturer's instructions. IL-1 $\alpha$ concentrations were calculated based on the standard curve, using standards provided with the kit. The detection range was $1.25-125 \mathrm{pg} / \mathrm{mL}$, and all values below the detection limit were recorded as half of the lowest concentration measured.

\section{Statistical analyses}

GraphPad Prism6 ${ }^{\circ}$ (GraphPad Software, USA), STATA version 11.0 (StataCorp, USA) and $\mathrm{R}$ were used for descriptive and statistical analyses and to generate graphs. Planned description of continuous variables with means, medians and standard deviations, as appropriate, were calculated. Categorical variables were described as proportions. Mann-Whitney $U$ tests were used to compare groups of continuous variables and relative risk (RR) was used for categorical variables. 95\% confidence intervals and $p$-values $\leq 0.05$ were used to determine statistical significance.

\section{Results}

\section{Path to SAHPRA approval}

This trial intended to explore the regulatory environment in South Africa governing probiotic trials, in order to lay the foundation for future trials of novel probiotic products. Prior to conducting this randomized trial, no 
probiotic trial had been approved by the regulatory authorities in South Africa. Thus, discussions with SAHPRA authorities were initiated in March 2016, as a decision on whether a full application for the trial was necessary, given that this was a randomized trial with a vaginally applied product, or whether a notification application was required. Currently, already available OTC probiotics (even those applied topically) are not considered or regulated as a medicine in South Africa but rather as a health supplement. Typically, the regulator requires full applications for products not registered in South Africa or for those not being used for their registered indication, dose, or formulation. Alternatively, SAHPRA notification is required for phase IV clinical studies of an approved medication within its approved dosage, formulation and indication. SAHPRA finally confirmed that the trial did not require a full application but rather a notification application, which was submitted to SAHPRA and approved (SAHRPA Ref 20,161,201).

\section{Cohort behavioural and biomedical characteristics}

Between 30 October 2017 and 22 March 2018, a total of 96 women seeking care for vaginal discharge were screened for eligibility (Fig. 1), of which the majority $(n=$ 90) were recruited via the UCT Student Wellness Centre. One woman tested HIV positive at screening, and thus was excluded and referred for care. Of 95 women who were eligible for screening, 43 women $(45.3 \%)$ were confirmed to have BV (Nugent 7-10; Table 1). Given that we recruited symptomatic women, this ratio confirms that vaginal discharge is a very imprecise tool for predicting the presence of BV [14], with a positive predictive value of only $45.3 \%$ in this cohort. In addition, $17.9 \%$ (17/95) had an STI, with $T$. vaginalis $(9.5 \%, 9 / 95)$ and $C$. trachomatis $(8.4 \%, 8 / 95)$ being the most common STIs detected. Of the $43 \mathrm{BV}$ positive women, 33 were eligible for randomization (BV+ but STI-).

Of the 33 women who were eligible, three were not interested in participating further. Therefore, 12/30 were randomized to the SOC arm (vaginal metronidazole alone; 5 days), while 18/30 were randomized to the intervention arm (vaginal metronidazole for 5 days, followed by 15 days of oral/vaginal probiotics). Randomised women were a median age of 22 years (IQR 20-26 years) old, predominantly single $(26 / 30,86.7 \%)$, and selfidentified as black $(20 / 30,66.7 \%)$. Their median age at sexual debut was reported to be 17 years (IQR 1619 years) with a median of five lifetime sexual partners (IQR 3-8), and reporting of oral sex was common (21/ $30,70.0 \%)$. About half (18/30) reported regular condom use, and few $(n=4)$ reported previously being diagnosed or treated for an STI (Table 2). Ninety-three percent (28/30) reported a history of chronic vaginal discharge, and more than half (20/30) reported previous use of prescription medicine to reduce vaginal discharge and malodour. Almost half $(14 / 30)$ reported that they were currently smoking, a factor that has previously been associated with the risk of BV [29-31]. Similarly, vaginal cleansing practices have been described as risk factor for BV [32-34], and more than half (17/30) reported practicing some kind of cleansing, including douching, using their fingers, water or soap to clean their vaginas internally (Table 2). More than half used tampons while menstruating, suggesting that they may likely be comfortable with the vaginal application of the probiotic (Table 2). None of the socio-behavioural characteristics evaluated differed by study arm.

\section{Adherence and safety}

Women attended a total of 143 visits, with the majority (25/ 30) completing all visits (Fig. 1) and all women (30/30) completing the entire five-day course of metronidazole. All women randomised to the probiotic (18/18) completed the course of oral probiotic capsules, and the majority (16/18) also completed the vaginal probiotic spray.

Overall, a total of 110 adverse events (AEs) were recorded over the course of the study. Most were mild (WHO grade 1-2, 109/110, 99.1\%) and unrelated to study product use $(76.4 \% ; 84 / 110)$, including headaches $(n=20)$, flu-like symptoms $(n=18)$, STI acquisition, including C. trachomatis $(n=8), T$. vaginalis $(n=$ 7), M. genitalium $(n=5)$ and $N$. gonorrhoea $(n=1)$, menstrual pain $(n=7)$, gastro-intestinal complaints $(n=5)$, temporary vaginal discomfort related to vaginal intercourse $(n=7)$, anaemia $(n=2)$, cat allergy $(n=1)$, buttock pain $(n=1)$, and anxiety $(n=1)$. It was concerning that more than half of the women $(53.3 \%$, 16/30) acquired an STI over the course of the study, supporting that BV is considered a risk factor for acquisition of STIs [7, 8]. Although BV has also been described as risk factor for urinary tract infections [35], none were reported by the participants throughout the course of the study.

Of AEs considered to be related to study products $(n=26)$, the majority was associated with vaginal metronidazole use and included previously describe side effects of vaginal metronidazole gel [36], including vaginal itching/irritation $(9 / 30,30.0 \%)$, candida infections $(5 / 30,16.7 \%)$, discomfort $(3 / 30,10.0 \%)$, increased discharge $(2 / 30,6.7 \%)$, spotting $(1 / 30,3.3 \%)$, or constipation $(1 / 30,3.3 \%)$. One third of the women administering probiotics $(5 / 18,27.8 \%)$ reported AEs after vaginal probiotic use, including vaginal itching/discomfort $(2 / 18,11.1 \%)$, increased vaginal discharge $(1 / 18$, $5.6 \%)$, increased nipple sensitivity $(1 / 18,5.6 \%)$, and nausea $(1 / 18,5.6 \%)$. 


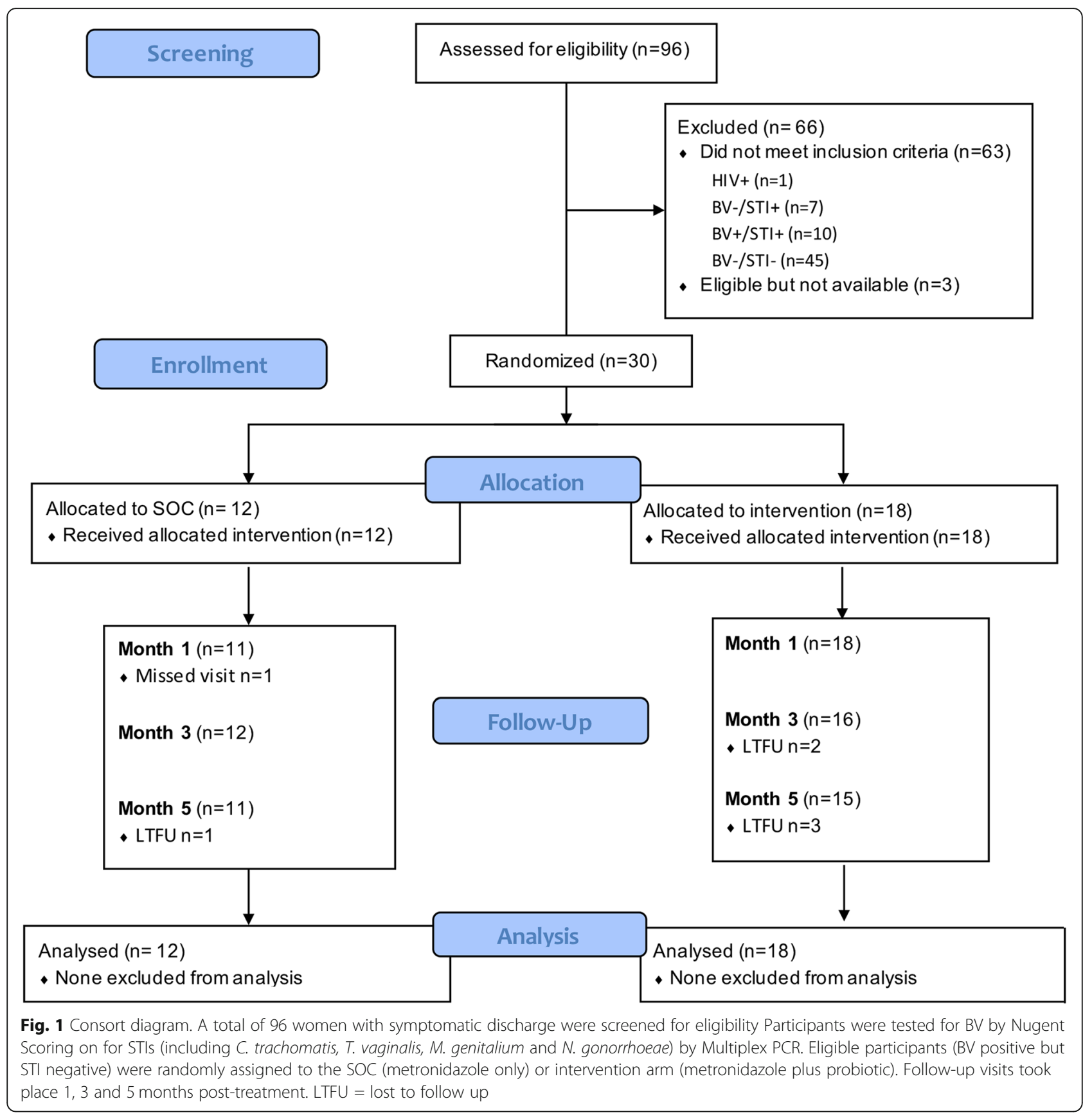

\section{Acceptability}

More than half of the women $(9 / 15,60.0 \%)$ reported that they liked using the combination probiotic because it was easy to use or resulted in improved vaginal symptoms (Fig. 2a). Most women (12/15, 80.0\%) reported that they preferred the oral capsule over the vaginal spray (Fig. 2b). Women reported that the vaginal spray was difficult to use, "messy and smelly" or that AEs occurred. The vast majority $(14 / 15,93.3 \%)$ believed that they received some benefit from this product and would buy it, primarily to prevent rather than to treat BV (Fig. 2c).
The majority $(13 / 15,86.7 \%)$ also said they would recommend it to other women. In terms of future product design, women reported that they would prefer a probiotic with oral application rather than a combination of oral and vaginal or vaginal only administration (Fig. 2d). If vaginal administration was required, women responded that they would prefer a tablet or gel rather than a tampon, spray or capsule. Women reported that they would prefer to buy the probiotic at pharmacies $(12 / 15,80.0 \%)$ compared to health stores, a grocery store or clinic (Fig. 2e). Women reported a preference for asking 
Table 1 Screening results

\begin{tabular}{ll}
\hline Age participant [years, median (IQR)] & $22(20-25)$ \\
\hline Self-identified race $[\%(\mathbf{n} / \mathbf{N})]$ & \\
Black & $67.7(65 / 96)$ \\
Coloured & $19.8(19 / 96)$ \\
White & $12.5(12 / 96)$ \\
Bacterial vaginosis (Nugent Score 7-10) [\% (n/N)] ${ }^{\text {a }}$ & $45.3(43 / 95)$ \\
Bacterial and protozoal infections [\% (n/N)] & \\
T. vaginalis & $9.5(9 / 95)$ \\
C. trachomatis & $8.4(8 / 95)$ \\
M. genitalium & $3.2(3 / 95)$ \\
N. gonorrhoea & $2.1(2 / 95)$ \\
Eligible (BV+/STI-) [\% (n/N)] & $34.7(33 / 95)$ \\
\hline
\end{tabular}

${ }^{a}$ One participant tested HIV positive, thus screening was aborted nurses $(13 / 15,86.6 \%)$ or doctors $(11 / 15,73.3 \%)$ for advice about using probiotics for vaginal health rather than pharmacists or self-help on the internet (Fig. 2f). It was also important to note that none of the women reported to be willing to spend more than 200 South African rand (ZAR; USD11.40; 1:0.06), which was less than the cost of the probiotic tested in this trial (costing ZAR280; $\sim$ USD16.00).

\section{Comparing clinical outcomes in SOC and intervention arms}

This trial was intended as an exploratory study to test the local regulatory environment and acceptability of vaginal probiotics. However, we also conducted an exploratory intention-to-treat (ITT) analysis to estimate possible benefits of administration of this locally sourced probiotic on clinical outcomes. The majority of women

Table 2 Cohort characteristics at enrolment

\begin{tabular}{|c|c|c|}
\hline & $\operatorname{SOC} \boldsymbol{n}=12$ & Intervention $\boldsymbol{n}=18$ \\
\hline Age participant [years, median (IQR)] & $23(21-34)$ & $22(20-26)$ \\
\hline \multicolumn{3}{|l|}{ Self-identified race $[\%(n)]$} \\
\hline Black & $58.3(7)$ & $72.2(13)$ \\
\hline Coloured & $25.0(3)$ & $16.7(3)$ \\
\hline White & $16.7(2)$ & $11.1(2)$ \\
\hline Age menarche [years, median (IQR)] & $12(11-15)$ & $14(13-16)$ \\
\hline \multicolumn{3}{|l|}{ Marital Status [\% (n)] } \\
\hline Single & $83.3(10)$ & $88.9(16)$ \\
\hline Married & $8.3(1)$ & - \\
\hline Separated/Divorced & $8.3(1)$ & $11.1(2)$ \\
\hline \multicolumn{3}{|l|}{ Pregnancies and contraception [\% (n)] } \\
\hline Ever been pregnant & $25.0(3)$ & $27.8(5)$ \\
\hline Currently using hormonal contraception & $33.3(4)$ & $38.9(7)$ \\
\hline Reported current smoking [\% (n)] & $50.0(6)$ & $44.4(8)$ \\
\hline \multicolumn{3}{|l|}{ Sexual risk behaviour and sexual health } \\
\hline Age of sexual debut [median (IQR)] & $18(17-18)$ & $17(16-19)$ \\
\hline Number of lifetime partners [median (IQR)] & $5(3-8)$ & $4(3-8)$ \\
\hline Oral sex during last 6 months [\% (n)] & $58.3(7)$ & $77.8(14)$ \\
\hline Regular condom use during last 6 months [\% (n)] & $66.7(8)$ & $55.6(10)$ \\
\hline Ever been diagnosed or treated for a STI [\% (n)] & $8.3(1)$ & $16.7(3)$ \\
\hline Partner or participant STI in last 6 month [\% (n)] & - & $16.7(3)$ \\
\hline Long-term history of vaginal discharge [\% (n)] & $83.3(10)$ & $100(18)$ \\
\hline \multicolumn{3}{|l|}{ Vaginal product use [\% (n)] } \\
\hline Use of medicine from doctor/nurse & $58.3(7)$ & $72.2(13)$ \\
\hline Use of tampon & $25.0(3)$ & $16.7(3)$ \\
\hline Cleansing with fingers & $16.7(2)$ & $11.1(2)$ \\
\hline Cleansing with water & $25.0(3)$ & $33.3(6)$ \\
\hline Douching to clean vagina & - & $16.7(3)$ \\
\hline Cleansing with soap & $8.3(1)$ & $5.6(1)$ \\
\hline
\end{tabular}




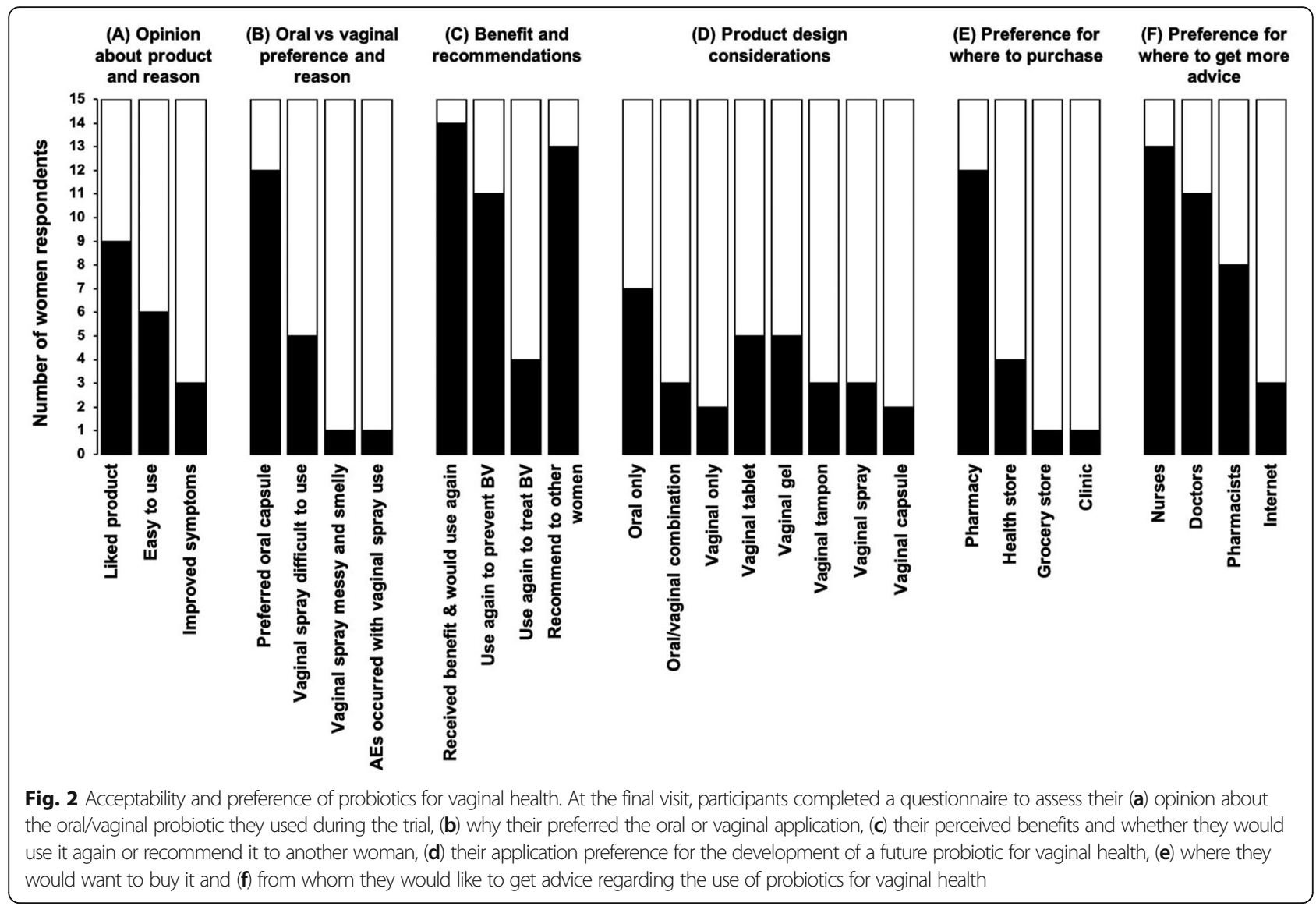

reported an improvement of their vaginal symptoms post-treatment, including discharge, colour and odour, with similar rates in the SOC and intervention arms (Table 3). Of these, the majority reported a decrease of vaginal discharge, and more than half reported a change in smell and/or colour of the discharge, independently of treatment arm.

The overall BV cure rate (defined as achieving a Nugent score $0-3)$ was $44.8 \%$ at month one, $46.4 \%$ at month three and $53.8 \%$ at month five. BV cure rates tended to be higher in the SOC arm $(63.6 \% ; 7 / 11)$ compared to the intervention arm $(33.3 \% ; 6 / 18 ; \mathrm{RR}=$ $0.52,95 \% \mathrm{CI}=0.24-1.16, p=0.109) 1$ month post-treatment (Fig. 3a). However, almost half of the cured women in the SOC arm (3/7) subsequently re-tested BV positive (Nugent $7-10$ ) at month 3 , while more than half of the cured women in the intervention arm (4/6) remained BV negative until the end of the trial.

In the SOC arm, 6/11 (54.5\%) women had a vaginal $\mathrm{pH}<4.51$ month after treatment, compared to $11 / 18$ (61.1\%) in the intervention group $(\mathrm{RR}=1.12,95 \% \mathrm{CI}=$ $0.58-2.15, p=0.733$; Fig. 3b). Similarly, no significant

Table 3 Reported vaginal symptoms post-treatment

\begin{tabular}{|c|c|c|c|c|c|c|}
\hline & \multicolumn{3}{|l|}{ Month 1} & \multicolumn{3}{|l|}{ Month 3} \\
\hline & $\overline{S O C}$ & Intervention & $\begin{array}{l}\text { RR }(95 \% C l)^{\mathbf{a}} \\
\boldsymbol{p} \text {-value }\end{array}$ & $\overline{S O C}$ & Intervention & $\begin{array}{l}\text { RR }(95 \% C l)^{\mathbf{a}} \\
\boldsymbol{p} \text {-value }\end{array}$ \\
\hline Discharge improvement [\%(n/N)] & $83.3(10 / 11)$ & $77.8(14 / 18)$ & $\begin{array}{l}0.86(0.63-1.17) \\
p=0.324\end{array}$ & $83.3(10 / 12)$ & $81.3(13 / 16)$ & $\begin{array}{l}0.96(0.69-1.34) \\
p=0.886\end{array}$ \\
\hline Less discharge & $90.0(9 / 10)$ & $78.6(11 / 14)$ & $\begin{array}{l}0.87(0.62-1.23) \\
p=0.438\end{array}$ & $90.0(9 / 10)$ & $61.5(8 / 13)$ & $\begin{array}{l}0.68(0.42-1.10) \\
p=0.118\end{array}$ \\
\hline Change in colour & $50.0(5 / 10)$ & $57.1(8 / 14)$ & $\begin{array}{l}1.14(0.53-2.46) \\
p=0.733\end{array}$ & $70.0(7 / 10)$ & $46.2(6 / 13)$ & $\begin{array}{l}0.66(0.32-1.35) \\
p=0.253\end{array}$ \\
\hline Change in smell & $70.0(7 / 10)$ & $71.4(10 / 14)$ & $\begin{array}{l}1.02(0.60-1.72) \\
p=0.940\end{array}$ & $80.0(8 / 10)$ & $61.5(8 / 13)$ & $\begin{array}{l}0.77(0.45-1.31) \\
p=0.332\end{array}$ \\
\hline
\end{tabular}

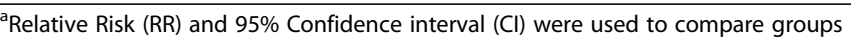




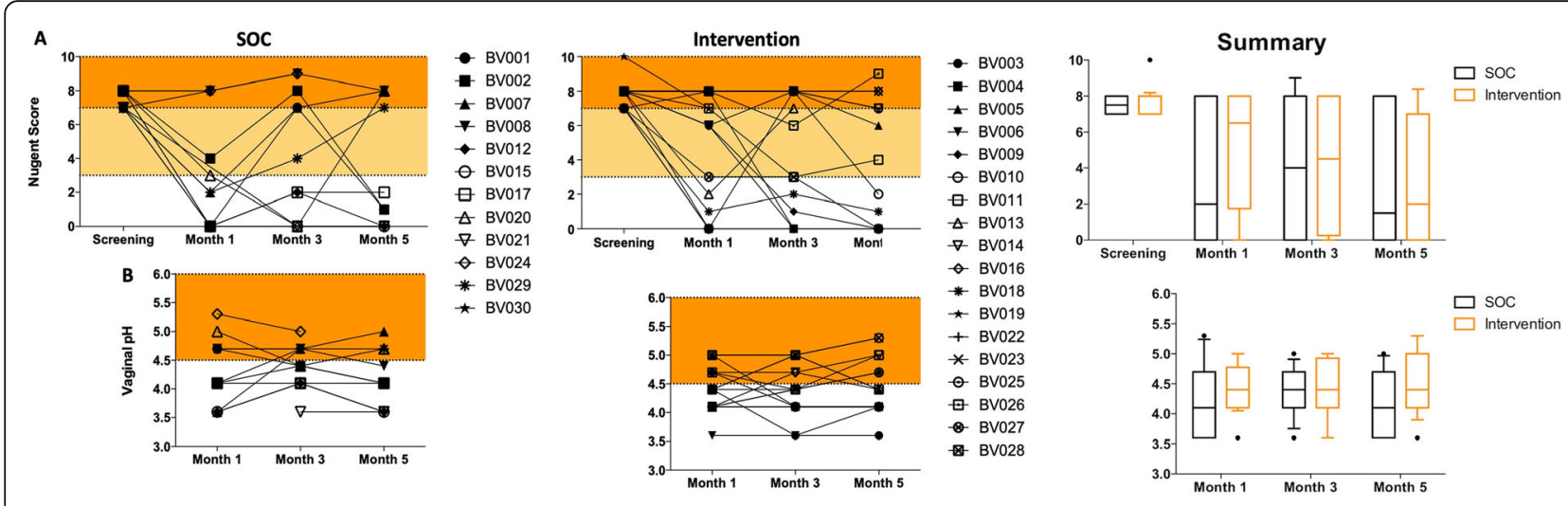

Fig. $3 \mathrm{BV}$ status and vaginal $\mathrm{pH}$ in the SOC and intervention group. a BV status was determined by Nugent scoring at screening, and one, three and five months post-treatment. Nugent Score $0-3=$ BV negative (white area); $4-6=$ BV intermediate (yellow) and 7-10 = BV positive (orange). $\mathbf{b}$ Vaginal pH was measured using color-fixed indicator strips one, three and five months post-treatment. A vaginal pH $<4.5$ (white area) is seen as protective. Each participant is represented by a symbol-coded dot, and the summaries show median and interquartile range

difference between the SOC and intervention arms were noted at later time points. Nugent scores correlated significantly with vaginal $\mathrm{pH}$ (Spearman rho $=0.71 ; p=$ 0.0001).

\section{Evaluating the presence of probiotic species in the genital tract}

To establish a framework on whether the bacterial species contained in the oral/vaginal probiotic colonised the
FGTs of women, concentrations of $L$. rhamnosus, $L$. acidophilus, B. bifidum and B. longum were measured before and after treatment (Fig. 4a). The majority of women (20/30) had detectable concentrations of L. acidophilus at baseline, although few had detectable levels of L. rhamnosus (2/30), B. bifidum (2/30) and B. longum $(8 / 30)$. However, we found no evidence of colonization of any of the bacterial species contained in the probiotic formulation post-treatment (Fig. 4a).

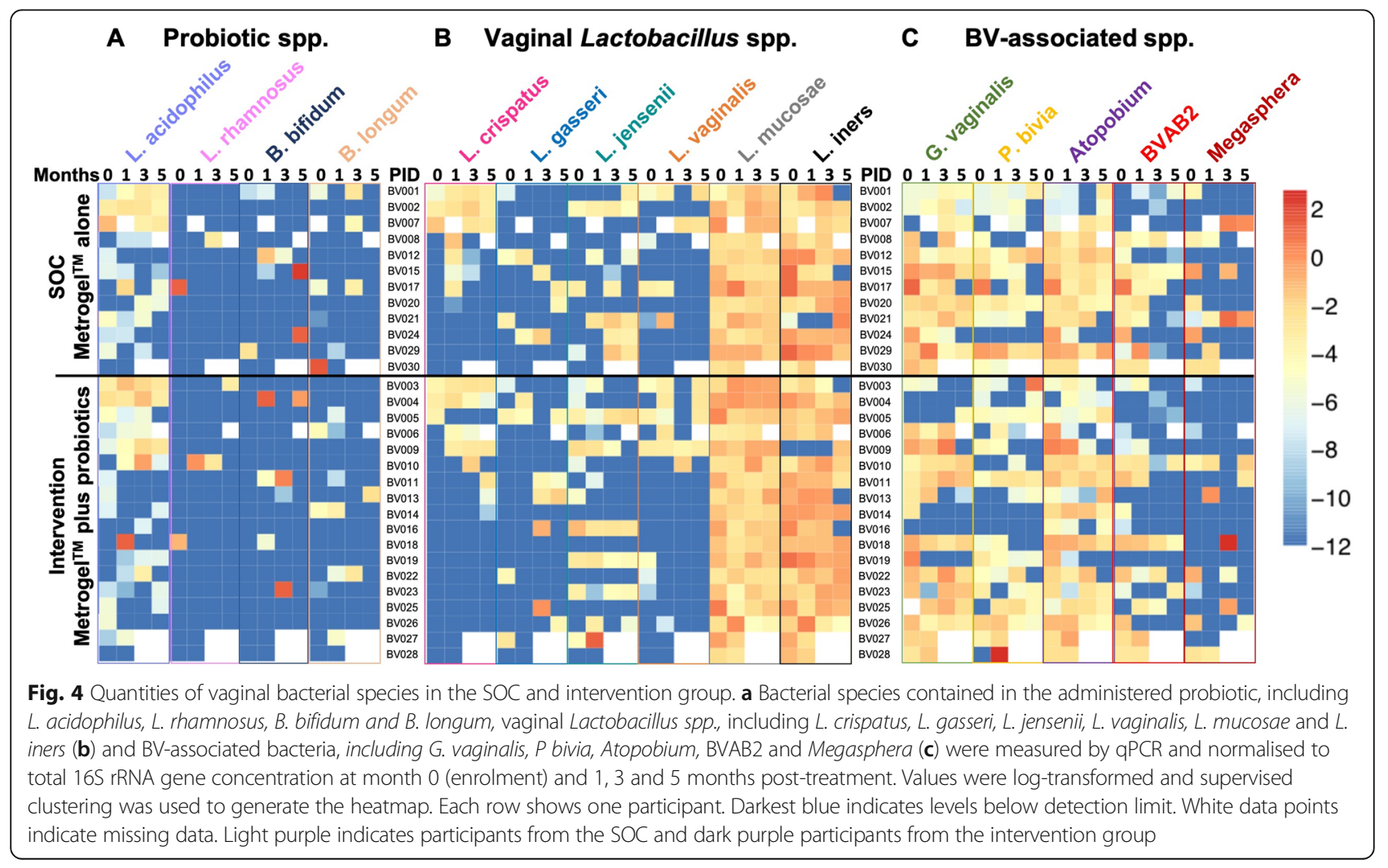


Commensal Lactobacillus and BV-associated communities following BV treatment

Most women had very low concentrations of $L$. crispatus, L. gasseri, L. jensenii and L. vaginalis before treatment, as expected (Fig. 4b). While some women showed increased concentrations of beneficial vaginal Lactobacillus spp. 1 month after treatment, others did not, and this did not differ by study arm. $L$. mucosae and $L$. iners were more commonly detected and concentrations were generally higher than those of other Lactobacillus spp. (Fig. 4b).

In line with their BV diagnosis, most women had detectable concentrations of G. vaginalis (26/30), P. bivia (21/30) and A. vaginae (29/30) pre-treatment (Fig. 4c). The concentrations of these BV-associated bacteria remained high throughout the trial despite BV treatment, both in the SOC and intervention arm. While most women had BVAB2 (22/30) and some Megasphera $(14 / 30)$ present pre-treatment, only some women lost or had decreased quantities of these bacterial species posttreatment, irrespective of study arm (Fig. 4c).

\section{Genital inflammation and interactions between the host and vaginal microbiota}

Genital IL-1 $\alpha$, a marker of inflammation [37], decreased after treatment in most women, albeit not significantly. However, levels of IL-1 $\alpha$ increased again quickly to those measure pre-treatment (Fig. 5). Adjusting for STIs acquired during the trial had no impact on this observation. While IL- $1 \alpha$ concentrations did not correlate with presence or absence of most Lactobacillus spp. and none of the BV-associated organisms, it correlated with $L$. iners concentrations 1 month (Spearman $\mathrm{r}=0.368, p=$ 0.049 ), and 3 months post-treatment (Spearman $\mathrm{r}=$ $0.373, p=0.055)$.

\section{Discussion}

In the present study, we evaluated the regulatory environment for conducting probiotic trials in South Africa. SAHPRA required a notification application, as the probiotic was available OTC in South Africa and considered a health supplement. The use of a vaginal/oral probiotic combination was well accepted among South African women included in this exploratory study and was associated with few product-related AEs. While this study was not sufficiently powered to test efficacy of this convenient OTC probiotic in South African women, we observed no beneficial clinical effect of this adjunctive probiotic compared to vaginal metronidazole alone as SOC. Nonetheless, this exploratory trial provided valuable lessons for future probiotic trials of the same disease entity in the same population, with improved products and adequate sample sizes.

With regards to the regulatory landscape, SAHPRA regulates OTC probiotics currently as health supplements, independently of their route of administration and health claims being made, but labels must state that "This unregistered medicine has not been evaluated by the SAHPRA for its quality, safety or intended use" [38]. In contrast, all health claims for probiotics in the European Union have to be authorized by the European Food Safety Authority (EFSA). Any statement suggesting a relationship between a product and health outcomes is considered a health claim, including using the term "probiotic" on a product label [39]. Thus far, EFSA has rejected all submitted health claims for probiotics [39]. Further, vaginally applied probiotics used to be regulated as medical devices, with even stricter regulations, standards and certification processes than orally applied products. Recent changes in the Medical Device Regulation state that living organisms are no longer acceptable as ingredients for medical devices from 2020, thus currently marketed vaginally applied probiotic products will have to either be re-classified or transferred to a new product category [40]. In the United States, most probiotics are classified as foods or dietary supplements, which are required to comply with Good Manufacturing Practice guidelines, but no quality or efficacy testing is required [39]. As in the European Union, no diseasespecific claims can be made on labels of dietary

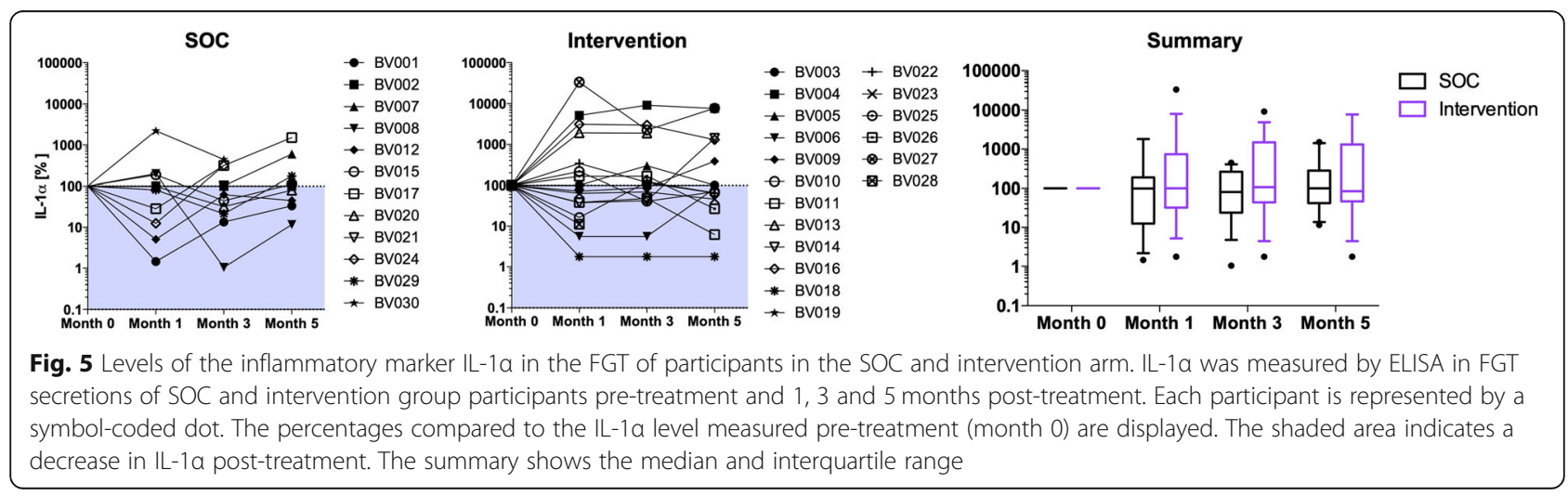


supplements, but functional claims, such as "improves vaginal health", can be made when accompanied by a disclaimer [39]. Thus, while SAHPRA, the regulatory body in South Africa, seems to be more concerned with product safety than misleading claims, sound scientific approaches should be required to demonstrate specific health benefits of commercially available probiotics to more closely align with regulatory bodies in Europe and the United States. Previous South African studies have shown poor correlation between label claims and actual probiotics content [41], thus post-market surveillance should be mandatory as well.

With regards to product design, women reportedly preferred the oral over the vaginal application of the probiotic, as the administration of the vaginal spray was uncomfortable and messy. Thus, for future probiotic product design women's preferences should be taken into consideration and probiotics containing wellselected vaginal Lactobacillus spp. should be administered orally. If topical administration is required, a vaginal tablet or gel would be preferred over a spray. Importantly, women were not willing to spend more than ZAR 200 ( USD11.40) for one treatment course. Given that $>60 \%$ of South African households earned less than ZAR 6367 ( USD368.55) per month according to the latest Census [42], the cost of one treatment course of the administered product per individual (ZAR 280; USD16.00) would use up $4.4 \%$ of the monthly income of those South African households. This highlights the need for the development of cheaper probiotics for vaginal health, making them available for those most in need of it.

The selected OTC oral/vaginal probiotic, like all those available in South Africa, does not contain Lactobacillus spp. that are commonly present in the FGT and associated with vaginal health, internationally and in South African women, such as $L$. crispatus, $L$. gasseri or $L$. jensenii $[19,43]$. Others have shown that vaginal Lactobacillus spp. are highly adapted to this ecological niche [44], and since the product did not contain those highly adapted Lactobacillus spp., they might have failed to colonize, which is in agreement with our microbiological results. For a successful colonization and subsequent ability to confer a health benefit to the host, the bacteria need to fulfil a broad range of other criteria including adherence to vaginal epithelial cells, production of lactic acid, decrease of vaginal $\mathrm{pH}$, decrease of inflammatory cytokines, and inhibition of BV-associated bacteria, such as G. vaginalis or P. bivia [43]. We have isolated and characterised the Lactobacillus strains contained in this OTC phenotypically and compared their characteristics to vaginal Lactobacillus strains from healthy South African women [43]. We did in fact find that vaginal Lactobacillus strains largely performed better in these in vitro assays than the strains currently used in probiotics for vaginal health, suggesting that it might not be ideal to include these strains in commercial probiotics for vaginal health.

Based on this experience with the South African regulatory body SAHPRA, we have some important insights for the design of future probiotic trials in South Africa. Clinical studies should test for BV cure shortly after treatment completion to minimize the likelihood that women have a recurrent BV event, in order to differentiate BV cure rates from confounding repeat episodes. Further, including a comparison with vaginal metronidazole gel alone or in combination with probiotic is more similar to a superiority trial rather than placebocontrolled [45], which is likely to make an efficacy trial with probiotics more difficult to power. Finally, we used vaginal metronidazole gel instead of oral metronidazole, which is more commonly used in South Africa for treating BV due to its lower cost. However, vaginal metronidazole gel is thought to be more effective and have less systemic side effects than the cheaper oral formulation [46, 47], which again should be taken into account when performing power calculations.

One interesting microbiological observation made during this study was that concentrations of vaginal $L$. iners correlated positively with the inflammatory cytokine IL$1 \alpha$. This supports literature suggesting that $L$. iners is not necessarily as beneficial as other common vaginal Lactobacillus spp. [48-50]. L. iners is often present during $\mathrm{BV}$, has complex nutritional requirements compared to other vaginal Lactobacillus spp., and encodes inerolysin, a pore-forming toxin that is related to G. vaginalisencoded vaginolysin [50]. The high inflammation associated with $L$. iners in our study suggests that rather than only treating women with $\mathrm{BV}$, also women with an $L$. iners-dominated microbiota and high genital inflammation could benefit from well-designed probiotics for vaginal health.

An important limitation of this study was the small number of participants; although this was intended as an exploratory study to test the regulatory environment in South Africa and the acceptability/preference of oral versus topical application. In addition, administration of the study drugs was self-reported and vaginal $\mathrm{pH}$ was not being measured pre-treatment. It was also unexpected that genital tract IL- $1 \alpha$ levels differed at baseline between randomized groups, which is difficult to explain. Further, no $16 \mathrm{~S}$ rRNA gene sequencing to evaluate relative vaginal bacterial abundance was performed, neither was bacterial culture.

\section{Conclusions}

In a region with some of the highest rates of BV, STIs and HIV, it is critical that the local regulatory 
environment for conducting randomized trials of planned novel probiotic products is established. This randomized single-blinded trial provided important regulatory and clinical considerations critical in the design of future clinical trials, with larger sample sizes intended for safety and efficacy endpoints. This exploratory trial did suggest that oral and vaginal OTC probiotics were generally safe and acceptable in South African women with BV. Due to the critical need to manage BV better internationally and in South Africa, future doubleblind, randomized, placebo-controlled trials, using a probiotic product containing beneficial, well-characterised vaginal Lactobacillus strains are needed to conclusively determine the efficacy of adjunctive probiotics on BV cure and recurrence in South African women.

\section{Supplementary information}

Supplementary information accompanies this paper at https://doi.org/10. 1186/s12879-020-05210-4.

Additional file 1. Participant questionnaires. Questionnaires administered to the participants to capture data on demographics, women's reproductive and sexual health, use and preference of study products.

Additional file 2: Figure S1. Bacterial concentration per dose unit of the commercial probiotic. The CFU per dose of three boxes (pink, purple and red) of the probiotic lot containing oral capsules (C) and vaginal spray (S) was determined using serial dilutions and compared to the manufacturers claim of $2 \times 109$ CFU per dose (dotted line).

\section{Abbreviations}

BV: Bacterial vaginosis; BVAB2: Bacterial Vaginosis-Associated Bacterium 2; CFU: Colony-forming units; CRC: Clinical Research Centre; EFSA: European Food Safety Authority; FGT: Female genital tract; ICH: International Conference on Harmonisation; OTC: Over-the-counter; RCT: Randomized controlled trial; SA-GCP: South African Good Clinical Practice; SAHPRA: South African Health Products Regulatory Authority; sBHI: Brain Heart Infusion supplemented with $0.1 \%$ starch and $1 \%$ yeast; SOC: Standard of care; STI: Sexually transmitted infections; UCT: University of Cape Town; ZAR: South African Rand

\section{Acknowledgements}

We would like to thank the UCT CRC for their regulatory support and help in setting up and running the trial.

\section{Authors' contributions}

$\mathrm{AH}$ designed the trial, enrolled the cohort, performed the experiments, analysis and wrote the manuscript. RS and NM performed some of the experiments. HBJ and KM contributed to writing the paper. SLB and JSP designed the trial, enrolled the cohort and contributed to analysis and writing the paper. All authors have read and approved the manuscript.

\section{Funding}

The study was funded by DST-NRF CAPRISA Centre of Excellence in HIV Prevention (PI: J. Passmore). AUH received bursaries from the South African Poliomyelitis Research Foundation and National Research Foundation during her PhD, and Postgraduate Publication Incentive funding from the University of Cape Town. The funders had no role the design of the study and collection, analysis, and interpretation of data and in writing the manuscript.

\section{Availability of data and materials}

The datasets used and/or analysed during the current study are available from the corresponding author on reasonable request.

\section{Ethics approval and consent to participate}

Approval for this clinical trial was obtained from University of Cape Town (UCT) Human Research Ethics Committee (HREC Ref 706/2016) and the South African National Health Research Ethics Council (NHREC Ref 4579). The trial was registered with the South African National Clinical Trial Register of the Department of Health (DOH-27-1117-5579; PI: S. Barnabas) and conducted in full compliance with South African Good Clinical Practice (SAGCP) and International Conference on Harmonisation (ICH)-GCP, supported by the UCT Clinical Research Centre (CRC). Before undergoing any trialrelated procedures, all women provided written informed consent.

\section{Consent for publication}

Not applicable.

\section{Competing interests}

None of the authors reported any conflict of interest. We confirm that none of the manufacturers were involved in the design or testing of this product and did not contribute financially in any way towards the conduct of this study. In addition, we confirm that none of the authors involved in this study are associated in any way financially or otherwise with the manufacturers.

\section{Author details}

${ }^{1}$ Division of Medical Virology, Faculty of Health Sciences, Institute of Infectious Disease and Molecular Medicine, University of Cape Town, Anzio Road, Observatory, Cape Town 7925, South Africa. ${ }^{2}$ NRF-DST CAPRISA Centre of Excellence in HIV Prevention, Cape Town, South Africa. ${ }^{3}$ School of Laboratory Medicine and Medical Sciences, University of Kwa-Zulu Natal, Durban, South Africa. ${ }^{4}$ National Health Laboratory Service, Durban, South Africa. ${ }^{5}$ Seattle Children's Hospital, Seattle, USA. ${ }^{6}$ Family Centre for Research with Ubuntu, Stellenbosch University, Tygerberg, South Africa.

Received: 10 February 2020 Accepted: 29 June 2020

Published online: 10 July 2020

\section{References}

1. Kenyon C, Colebunders R, Crucitti T. The global epidemiology of bacterial vaginosis: a systematic review. Am J Obstet Gynecol. 2013;209(6):505-23. Available from:. https://doi.org/10.1016/j.ajog.2013.05.006.

2. Gajer P, Brotman RM, Bai G, Sakamoto J, Schütte UME, Zhong X, et al. Temporal dynamics of the human vaginal microbiota. Sci Transl Med. 2012; 4(132):132ra52 Available from: http://stm.sciencemag.org/content/ scitransmed/4/132/132ra52.full.

3. Srinivasan S, Hoffman NG, Morgan MT, Matsen FA, Fiedler TL, Hall RW, et al, Bacterial communities in women with bacterial Vaginosis : high resolution phylogenetic analyses reveal relationships of microbiota to clinical criteria. PLoS One. 2012;7(6):e37818.

4. McKinnon LR, Achilles SL, Bradshaw CS, Burgener A, Crucitti T, Fredricks DN, et al. The evolving facets of bacterial vaginosis: implications for HIV transmission. AIDS Res Hum Retroviruses. 2019;35(3):219-28 Available from: https://www.ncbi.nlm.nih.gov/pubmed/30638028.

5. Haggerty $\mathrm{CL}$, Totten PA, Tang G, Astete SG, Ferris MJ, Norori J, et al. Identification of novel microbes associated with pelvic inflammatory disease and infertility. Sex Transm Infect. 2016; sextrans-2015-052285. Available from: http://sti.bmj.com/lookup/doi/10.1136/sextrans-2015-052285.

6. Nelson DB, Hanlon A, Nachamkin I, Haggerty C, Mastrogiannis DS, Liu C, et al. Early pregnancy changes in bacterial vaginosis-associated bacteria and preterm delivery. Paediatr Perinat Epidemiol. 2014;28(2):88-96.

7. Cohen CR, Lingappa JR, Baeten JM, Ngayo MO, Spiegel CA, Hong T, et al. Bacterial vaginosis associated with increased risk of female-to-male HIV-1 transmission: a prospective cohort analysis among african couples. PLoS Med. 2012;9(6):18,

8. Anahtar MN, Byrne EH, Doherty KE, Bowman BA, Yamamoto S, Soumillon M, et al. Inflammatory responses in the female genital tract. Immunity. 2016; 42(5):965-76.

9. Lennard K, Dabee S, Barnabas SL, Havyarimana E, Blakney A, Jaumdally SZ, et al. Microbial composition predicts genital tract inflammation and persistent bacterial vaginosis in South African adolescent females. Infect Immun. 2018;86(1):e00410-17.

10. Barrons $\mathrm{R}$, Tassone $\mathrm{D}$. Use of lactobacillus probiotics for bacterial genitourinary infections in women: a review. Clin Ther. 2008;30(3):453-68. 
11. Bradshaw CS, Morton AN, Hocking J, Garland SM, Morris MB, Moss LM, et al. High recurrence rates of bacterial vaginosis over the course of 12 months after oral metronidazole therapy and factors associated with recurrence. J Infect Dis. 2006;193(11):1478-86.

12. Johnson LF, Dorrington RE, Bradshaw D, Coetzee DJ. The effect of syndromic management interventions on the prevalence of sexually transmitted infections in South Africa. Sex Reprod Healthc. 2011;2(1):13-20.

13. Mlisana K, Naicker N, Werner L, Roberts L, Van Loggerenberg F, Baxter C, et al. Symptomatic vaginal discharge is a poor predictor of sexually transmitted infections and genital tract inflammation in high-risk women in South Africa. J Infect Dis. 2012;206(1):6-14

14. Barnabas SL, Dabee S, Passmore JS, Jaspan HB, Lewis DA, Jaumdally SZ, et al. Converging epidemics of sexually transmitted infections and bacterial vaginosis in southern African female adolescents at risk of HIV. Int J STD AIDS. 2017;0(0):1-9.

15. McKinnon LR, Liebenberg $L$, Yende-Zuma N, Archary D, Ngcapu S, Sivro A, et al. Genital inflammation undermines the effectiveness of tenofovir gel in preventing HIV acquisition in women. Nat Med. 2018;24(4):491-6.

16. Marcone V, Rocca G, Lichtner M, Calzolari E. Long-term vaginal administration of Lactobacillus rhamnosus as a complementary approach to management of bacterial vaginosis. Int J Gynecol Obstet [Internet]. 2010; 110:223-6. Available from:. https://doi.org/10.1016/j.ijgo.2010.04.025.

17. Vicariotto F, Mogna L, Del Piano M. Effectiveness of the two microorganisms lactobacillus formulated in slow-release vaginal tablets, in women affected by bacterial vaginosis. J Clin Gastroenterol. 2014;48:S106-12.

18. Li C, Wang T, Li Y, Zhang T, Wang Q, He J, et al. Probiotics for the treatment of women with bacterial vaginosis: a systematic review and meta-analysis of randomized clinical trials. Eur J Pharmacol. 2019;864(September):172660. Available from. https://doi.org/10.1016/j.ejphar.2019.172660

19. Lennard K, Dabee S, Barnabas SL, Havyarimana E, Blakney A, Jaumdally SZ, et al. Microbial composition predicts genital inflammation and persistent bacterial vaginosis in adolescent south African women. Infect Immun. 2017; 86(1):e00410-7.

20. Noyes N, Cho K, Ravel J, Forney LJ, Abdo Z. Associations between sexual habits, menstrual hygiene practices, demographics and the vaginal microbiome as revealed by Bayesian network analysis. PLoS One. 2018;13(1): e0191625.

21. Anahtar MN, Byrne EH, Fichorova RN, Kwon DS, Anahtar MN, Byrne EH, et al. Cervicovaginal Bacteria are a major modulator of host inflammatory responses in the female genital article Cervicovaginal Bacteria are a major modulator of host inflammatory responses in the female genital tract. Immunity. 2015:42(5):965-76.

22. Anukam K, Osazuwa E, Ahonkhai I, Ngwu M, Osemene G, Bruce AW, et al. Augmentation of antimicrobial metronidazole therapy of bacterial vaginosis with oral probiotic Lactobacillus rhamnosus GR-1 and Lactobacillus reuteri RC-14: randomized, double-blind, placebo controlled trial. Microbes Infect. 2006;8(6):1450-4.

23. Irvine SL, Hummelen R, Hekmat S, Looman CWN, Habbema JDF, Reid G. Probiotic yogurt consumption is associated with an increase of CD4 count among people living with HIV / AIDS. J Clin Gastroenterol. 2010;44(9):201-5.

24. Marcotte H, Larsson PG, Andersen KK, Zuo F, Mikkelsen LS, Brandsborg E, et al. An exploratory pilot study evaluating the supplementation of standard antibiotic therapy with probiotic lactobacilli in south African women with bacterial vaginosis. BMC Infect Dis. 2019;19(1):1-15.

25. Happel A-U, Jaumdally SZ, Pidwell T, Cornelius T, Jaspan HB, Froissart R, et al. Probiotics for vaginal health in South Africa : what is on retailers shelves ? BMC Womens Health. 2017;17(7) Available from:. https://doi.org/ 10.1186/s12905-017-0362-6.

26. Petricevic L, Unger FM, Viernstein H, Kiss H. Randomized, double-blind, placebo-controlled study of oral lactobacilli to improve the vaginal flora of postmenopausal women. Eur J Obstet Gynecol Reprod Biol. 2008;141:54-7.

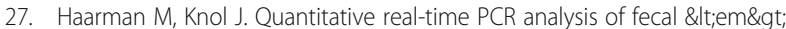
Lactobacillus\&lt;/em\&gt; species in infants receiving a prebiotic infant formula. Appl Environ Microbiol. 2006;72(4):2359 LP-2365 Available from: http://aem.asm.org/content/72/4/2359.abstract.

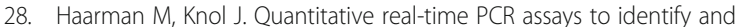
quantify fecal \&lt;em\&gt;Bifidobacterium\&lt;/em\&gt; species in infants receiving a prebiotic infant formula. Appl Environ Microbiol. 2005;71(5):2318 LP-2324 Available from: http://aem.asm.org/content/71/5/2318.abstract.

29. Hellberg D, Nilsson S, Mardh P-A. Bacterial vaginosis and smoking. Int J STD AIDS. 2000;11:603-6.
30. Brotman RM, He X, Gajer P, Fadrosh D, Sharma E, Mongodin EF, et al. Association between cigarette smoking and the vaginal microbiota : a pilot study. BMC Infect Dis. 2014;14:471.

31. Cherpes TL, Hillier SL, Meyn LA, Busch JL, Krohn MA. A delicate balance: risk factors for acquisition of bacterial vaginosis include sexual activity, absence of hydrogen peroxide-producing lactobacilli, black race, and positive herpes simplex virus type 2 serology. Sex Transm Dis. 2008;35(1):78-83.

32. Martino JL, Vermund $\mathrm{SH}$. Vaginal douching: evidence for risks or benefits to women's health. Epidemiol Rev. 2002;24(2):109-24 Available from: https:// pubmed.ncbi.nlm.nih.gov/12762087.

33. Brotman RM, Klebanoff MA, Nansel TR, Andrews WW, Jane R, Zhang J, et al. A longitudinal study of vaginal douching and bacterial Vaginosis - a marginal structural modeling analysis. Am J Epidemiol. 2008;168(2):188-96.

34. Mbizvo ME, Musya SE, Stray-Pedersen B, Chirenje Z, Hussain A. Bacterial vaginosis and intravaginal practices: association with HIV. Cent Afr J Med. 2004;50(5-6):41-6.

35. Storme O, Tirán Saucedo J, Garcia-Mora A, Dehesa-Dávila M, Naber KG. Risk factors and predisposing conditions for urinary tract infection. Ther Adv Urol [Internet]. 2019;11:1756287218814382 Available from: https://pubmed. ncbi.nlm.nih.gov/31105772.

36. Davis S. Bacterial vaginosis and its treatment with a focus on metronidazole gel. SA Pharm Assist. 2019:19(3):10-2.

37. Masson L, Arnold KB, Little F, Mlisana K, Lewis DA, Mkhize N, et al. Inflammatory cytokine biomarkers to identify women with asymptomatic sexually transmitted infections and bacterial vaginosis who are at high risk of HIV infection. Sex Transm Infect. 2016;92(3):186-93.

38. SAHPRA. Complementary medicines. 2020 [cited 2020 Jun 2]. Available from: https://www.sahpra.org.za/complementary-medicines/.

39. de Simone C. The unregulated probiotic market. Clin Gastroenterol Hepatol. 2019;17(5):809-17 Available from: http://www.sciencedirect.com/science/ article/pii/S1542356518300843.

40. Maresova P, Hajek L, Krejcar O, Storek M, Kuca K. New regulations on medical devices in Europe: are they an opportunity for growth? Adm Sci. 2020;10(1):16.

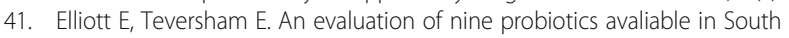
Africa. Samj. 2004;94(2):121-4.

42. STATSSA. South African national census. 2011. [cited 2020 Jun 1]. Available from: http://www.statssa.gov.za/.

43. Happel A-U, Kullin B, Gamieldien H, Wentzel N, Zauchenberger CZ, Jaspan HB, et al. Exploring potential of vaginal lactobacillus isolates from South African women for enhancing treatment for bacterial vaginosis. PLOS Pathog. 2020; 16(6):e1008559. Available from. https://doi.org/10.1371/journal.ppat.1008559.

44. Mendes-soares H, Suzuki H, Hickey RJ, Forney LJ. Comparative functional genomics of lactobacillus spp. Reveals possible mechanisms for specialization of vaginal lactobacilli to their environment. J Bacteriol. 2014; 196(7):1458-70.

45. Goldfarb D. Superiority trials, non-inferiority trials, and prisoners of the 2 sided null hypothesis. Evid Based Med. 2004;9(4):100.

46. Bistoletti P, Fredricsson B, Hagström B, Nord C-E. Comparison of Oral and vaginal metronidazole therapy for nonspecific bacterial Vaginosis. Gynecol Obstet Invest. 1986;21(3):144-9 Available from: https://www.karger.com/ DOI/10.1159/000298944

47. Koumans EH, Markowitz LE, Hogan V, Group CDCBWW. Indications for therapy and treatment recommendations for bacterial vaginosis in nonpregnant and pregnant women: a synthesis of data. Clin Infect Dis. 2002;35(Supplement_2): S152-72. Available from. https://doi.org/10.1086/342103.

48. Macklaim JM, Fernandes AD, Di Bella JM, Hammond J-A, Reid G, Gloor GB. Comparative meta-RNA-seq of the vaginal microbiota and differential expression by Lactobacillus iners in health and dysbiosis. Microbiome. 2013; 1(1):12 Available from: http://www.pubmedcentral.nih.gov/articlerender. fcgi?artid=3971606\&tool=pmcentrez\&rendertype=abstract.

49. De Seta F, Campisciano G, Zanotta N, Ricci G, Comar M. The vaginal community state types microbiome-immune network as key factor for bacterial vaginosis and aerobic vaginitis. Front Microbiol. 2019;10:2451 Available from: https://pubmed.ncbi.nlm.nih.gov/31736898.

50. Petrova MI, Reid G, Vaneechoutte M, Lebeer S. Lactobacillus iners: friend or foe ? Trends Microbiol. 2017;25(3):182-91. Available from:. https://doi.org/10. 1016/j.tim.2016.11.007.

\section{Publisher's Note}

Springer Nature remains neutral with regard to jurisdictional claims in published maps and institutional affiliations. 